\title{
Crying girl on the border: a colonialidade de gênero na fronteira das imagens
}

\author{
Angie Biondil \\ Ângela Cristina Salgueiro Marques²
}

\section{Resumo}

As discussões empreendidas pelo pensamento decolonial têm levado pesquisadoras e pesquisadores à revisão crítica das práticas mediáticas no âmbito da produção e circulação de imagens. As maneiras de representar sujeitos sem considerar os marcadores de gênero, raça, classe, etnia, em interseccionalidade, são questionadas como sínteses visuais redutoras de complexos processos engendrados por formas subjacentes do capitalismo. Neste texto, propomos uma reflexão crítica acerca dos modos como a imagem jornalística ainda circunscreve um lugar específico ao sujeito vulnerável, tomando como uma base exemplar a fotografia vencedora do prêmio internacional World Press Photo, em 2019.

Palavras-chave: Fotojornalismo. Gênero 2. Migrantes 3.

\section{Crying girl on the border: gender coloniality on the border of images}

\section{Abstract}

The discussions undertaken by decolonial thought have led researchers to a critical review of media practices in the scope of image production and circulation. The different ways to represent subjects without considering the markers of gender, race, class, ethnicity, in intersectionality, are questioned as visual syntheses that reduces complex processes engendered by the underlying forms of capitalism. In this text, we propose a critical reflection on the ways in which journalistic image circumscribes a specific role for vulnerable people, taking as an exemplary base the photograph that won the World Press Photo international award in 2019.

\footnotetext{
1 Professora do Programa de Pós-graduação em Comunicação e Linguagens da Universidade Tuiuti do Paraná. Doutora em Comunicação Social pela UFMG. E-mail: angiebiondina@gmail.com

2 Professora do Programa de Pós-graduação em Comunicação Social da UFMG. Doutora em Comunicação Social pela UFMG. E-mail: angelasalgueiro@gmail.com
} 
Keywords: Photojournalism 1. Gender 2. Migrants 3.

\title{
Introdução
}

Há algum tempo, as pesquisas em comunicação têm empreendido esforços para compreender como imagens concernentes ao jornalismo se referem, demonstram, indicam, retratam, enfim, representam os sujeitos comuns, anônimos, imersos em suas vidas e acontecimentos cotidianos. A observação e análise da circulação destas diversas imagens, bem como a produção de discursos e significados que the são extensivos são recorrentes objetos de estudo na área.

\begin{abstract}
Interessados não tanto nas imagens em si, mas nas relações que podem ser traçadas entre elas a partir de sua presença em contextos diversos, esses estudos se concentram em observar as potências da imagem no tempo - sua aparição, suas reverberações, a dissolução e desaparecimento, bem como seu retorno a partir da persistência como parte de um imaginário (MARTINO; MARQUES, 2020, p. 85)
\end{abstract}

Embora figurem frequentemente nos espaços visuais e narrativos das diferentes mídias, observa-se, no entanto, que a condição de homens, mulheres e crianças, muitas vezes, são mantidas invisíveis mesmo quando alcançadas pelas câmeras fotográficas e profissionais da imprensa, uma vez que Ihe é conferido apenas um caráter ilustrativo ou exemplar junto aos diversos temas que constituem acontecimentos e perfazem o contexto jornalístico. As narrativas jornalísticas, muitas vezes, buscam representar as camadas populares e vulneráveis localizando-os a partir de matrizes socioculturais pré-definidas. $\mathrm{E}$, deste modo, demarcam tanto os notórios "condicionantes estruturais quanto os processos de subjetivação em que se encontram inseridos empiricamente os diferentes atores" (LOPES, 2018, p.41).

Segundo Persichetti (2006, p. 184), a revisão dos critérios que animam o fotojornalismo, em especial, não é uma tarefa nova e apresenta uma literatura crítica que destaca pelo menos dois grandes momentos de sua prática, a saber, uma ligada ao aspecto idealizado (ainda moderno) de retratar a realidade mesma, na qual a imagem seria dada como a própria informação, e outra ligada ao aspecto expressivo (advindo a partir dos anos de 1990), na qual a prevalência da imagem passa a compor ou criar o próprio fato ou o acontecimento.

A discussão sobre os meios de comunicação nos leva ao uso político da imagem. As fotografias servem para construir fatos. Muitas imagens foram feitas por fotojornalistas, mas por motivos muitos e diversos, só 


\section{REVISTA PAUTA GERAL \\ ESTUDOS EM JORNALISMO \\ 10.5212/RevistaPautaGeral.v.7.15837}

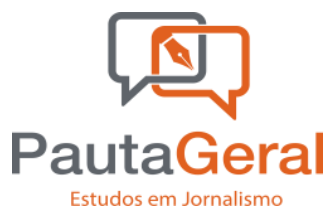

algumas destas imagens se tornaram públicas, a imagem de um evento. Estas fotografias se transformaram no próprio evento, são monumentos. (D'AUTILIA apud PERSICHETTI, 2006, p. 185).

Vale observar, portanto, se - e como - sujeitos comuns ainda figurariam como exemplares notórios dos acontecimentos através das imagens veiculadas em páginas de jornais, revistas ou portais de notícias. E, extensivamente, como tal representação estaria engendrada aos aspectos expressivos elaborados em imagens fotojornalísticas ainda hoje.

Em trabalhos anteriores (MARQUES; BIONDI, 2017, 2018, 2019) exploramos o tensionamento entre duas formas de representar sujeitos em situação de vulnerabilidade no fotojornalismo. Salientamos que, apesar da constante utilização de um léxico que geralmente pretende conferir-Ihes visibilidade, as imagens ainda tendem a invisibilizá-los a partir da reiteração de uma lógica de registro que considera discursos já enraizados sobre pobreza, dependência, vulnerabilidade e estigmas de gênero. Há racionalidades que reforçam modos de legibilidade e inteligibilidade das imagens a partir do acionamento de premissas, julgamentos, valores, predisposições afetivas, que permitem aos atores sociais reconhecerem e compreenderem os fatos a partir do que chamamos de enquadramentos consensuais. Assim, mesmo ganhando "visibilidade" nas páginas de jornais, sujeitos e grupos mais vulneráveis não se tornam socialmente inteligíveis e visualmente reconhecíveis. Como se esses sujeitos e grupos fossem menos dignos de valor diante do olhar de um espectador que, presumivelmente, as interroga e avalia seus modos de vida e condutas.

Todavia, acreditamos que as imagens fotojornalísticas são operações dialéticas que trabalham tanto para "representar" de maneira documental as vidas precárias, quanto no sentido de não apagar todos os vestígios e brechas que permitem o "aparecimento" e a figuração dos povos vulneráveis. Dito de outro modo, há uma possibilidade de, a partir de um deslocamento do olhar, revelar os desencaixes que escapam aos modos de captura e controle pelos aparatos governamentais e midiáticos. Assim, permitir a figuração e o aparecimento de corpos produzidos visualmente como precários e expostos na fotografia jornalística implica tanto explorar as formas discursivas de enquadramento consensual que acentuam sua desaparição, quanto em buscar indícios que possam evidenciar como tal enquadramento muitas vezes não resiste aos deslocamentos do olhar que, ao percorrer a imagem, duvida, oscila, encontra uma forma de conferir dignidade e reconhecimento aos sujeitos que ali figuram (MARQUES; BIONDI, 2017, 2018). 


\section{REVISTA PAUTA GERAL}

\section{ESTUDOS EM JORNALISMO}

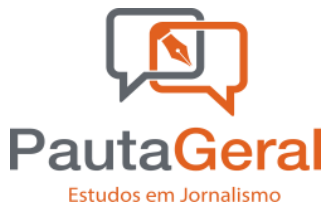

Estudos em Jornalismo

Ao mesmo tempo, nos últimos anos, o acirramento das discussões acerca do decolonialismo, sobretudo, a partir de pesquisas e publicações de obras centrais advindas de fora do eixo acadêmico europeu e norte-americano, têm levado pesquisadoras e pesquisadores à revisão crítica de certas práticas mediáticas, sobretudo, aquelas que se referem ao âmbito da produção e circulação de imagens como conhecidos espaços produtores de enquadramentos e sentidos que conduzem à (in)visibilidade dos sujeitos comuns quando representados no âmbito jornalístico. Pesquisadores como CASTROGÓMEZ; GROSFOGUEL, 2007; CALLEGARO; LAGO, 2012; URANGA, 2005; CRUZ, 2017; 2019, têm destacado como certas produções mediáticas contemporâneas têm sido analisadas e refletidas a partir de uma perspectiva que lhes exige a desconstrução de paradigmas hegemônicos que ainda balizam as formas narrativas quando conferem "um rosto humano à notícia" (CRUZ, 2017, p.2).

No jornalismo, atualmente, as maneiras de representar sujeitos sem considerar os marcadores de gênero, raça, classe, sexualidade ou ainda etnia, em interseccionalidade ${ }^{3}$, são questionadas como sínteses visuais redutoras de complexos processos engendrados por formas subjacentes do capitalismo - entendido aqui tanto um modo de produção, quanto uma lógica ocidental moderna -, que ainda reverbera modelos de opressão e marcadores culturais estigmatizantes.

Assim, a expansão e aprofundamento de crises e sofrimentos de diversas populações e certos grupos sociais têm sido discutidas como tributárias dos modelos de opressão vividos, e ainda em vivências. A partir destas premissas iniciais, buscamos, neste texto, dar passagem a uma reflexão que contemple a crítica advinda do pensamento decolonial enfatizando um grave problema elaborado como um tema visual dos mais recorrentes no jornalismo: a migração. Para isso, tomamos como exemplo da discussão reflexiva aqui proposta, a imagem classificada como "a fotografia do ano", vencedora da maior láurea de fotojornalismo internacional, o World Press Photo, por entender que este tipo de premiação tanto postula as bases referencias da prática fotojornalística contemporânea quanto atribui legitimidade à produção de conteúdo veiculado de modo adjunto. Intitulada Crying girl on the border, a fotografia de John

3 Para fins de aprofundamento de pesquisa indicamos que a interseccionalidade, enquanto um termo conceitual, aparece cunhada no âmbito dos direitos humanos pela pesquisadora afro-estadunidense Kimberlé Crenshaw, em 2001. Seu potencial heurístico, contudo, já comparecia nas discussões empreendidas por pensadoras como Angela Davis, na obra Mulheres, raça e classe, de 1981. 
Moore, vencedora da edição de 2019, retrata a abordagem de agentes policiais norteamericanos a um grupo latino-americano composto, em sua maioria, por mulheres e crianças.

\section{Nas fronteiras, a colonialidade de gênero}

O pensamento decolonial tem buscado promover uma ruptura no grande modelo teórico e epistemológico moderno que até hoje ampara conceitos hegemônicos e universalismos. Segundo Castro-Gómez; Grosfoguel (2007, p.14), mesmo as produções e análises acadêmicas atuais ignoram epistemologias que são produzidas desde as margens, reproduzindo um eixo centralizador que uniformiza os saberes e mantém discursos e sujeitos aderidos às posições e categorias estigmatizantes.

Contemporaneamente, o que se apresenta é ainda uma espécie de modulação da agência de poder que constitui diferentes formas de assujeitamentos. Segundo Achille Mbembe (2018), esta "ocupação colonial tardia" apresenta facetas diferenciadas da primeira ocupação moderna, especificamente em sua combinação entre o disciplinar, a biopolítica e a necropolítica; arranjo denominado pelo autor de "necropoder".

Se anteriormente, conforme indica Mbembe (2018), a colonialidade moderna ocorria em termos de ocupação forçada, com objetivos de conquista, aquisição e gerência de territórios, nos tempos atuais, as "máquinas de guerra" estão encarnadas em práticas difusas e polimorfas, cujo exercício maior é o de decisão sobre vida e morte, no sentido diluído de suas percepções de valor, mas também de materializações acerca das diferentes formas de inclusão e exclusão de sujeitos. Trata-se, portanto, de um outro modo de governamentalidade, segundo o autor, que não se importaria com dimensões internas ou externas, em termos geográficos e físicos, mas de corpos feitos territórios que deveriam seguir o fluxo controlado e a demarcação dos movimentos de interesses de um capital imaterial, simbólico, indicado como "esta nova era da mobilidade global" (MBEMBE, 2018, p. 52).

A afirmação de uma autoridade suprema em um determinado espaço político não se dá facilmente. Em vez disso, emerge um mosaico de direitos de governar incompletos e sobrepostos, disfarçados e emaranhados, nos quais sobejam diferentes instâncias jurídicas de facto geograficamente entrelaçadas, e nas quais abundam fidelidades plurais, suseranias assimétricas e enclaves. Nessa organização heterônima de direitos territoriais e reivindicações, faz pouco sentido insistir na distinção entre campos políticos 'interno' e 'externo', separados por limites claramente demarcados. (MBEMBE, 2018, p.51) 


\section{REVISTA PAUTA GERAL}

\section{ESTUDOS EM JORNALISMO}

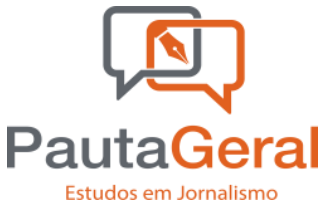

Estudos em Jornalismo

Deste modo, nos parece importante sublinhar o modo através do qual o pensamento decolonial tem observado discursos e práticas que instituem modelos de exclusões, invisibilidades e assujeitamentos, sobretudo quando inscritos em práticas mediáticas, cujos discursos constituem ainda importantes elementos socializantes de linguagem e significação acerca dos sujeitos figurados. Em diálogo com o pensamento da pesquisadora María Lugones (2014), a lógica categorial, atomizada e hierárquica sempre foi necessária à manutenção de um sistema dicotômico que ainda separa sujeitos e posições econômicas, mas também ecológicas, cosmológicas e espirituais, como aspecto central da roupagem de um capitalismo colonialista.

Neste processo, grandes contingentes populacionais padeceram dos modelos de opressão colonial, tradicionalmente baseados no escravismo, mas que reverbera, ainda hoje, nas vidas, corpos e subjetividades de sujeitos vilipendiados de direitos e cidadania, quando não da própria condição de humanos. Segundo ela, o exercício de revisar os modelos hegemônicos que impuseram categorias como universais perpassa não apenas uma revisão teórica e conceitual das mais urgentes, mas procura fazer jus a um modo de pensamento que já demarcava a distinção às maneiras de compreender e dar visibilidade aos aspectos constituidores de assujeitamentos.

Neste contexto é que comparecem, nas discussões atuais, os marcadores de gênero, raça, classe, etnia, sexualidade que, quando sobrepostos uns aos outros, correspondem a uma classificação identitária estanque e fragmentada que aparta ainda mais os sujeitos em uma dinâmica social, cultural e política, quando, na realidade, precisam ser pensados em seus contextos materiais e nas situações concretas de atravessamentos, ou seja, em intersecção. A interseccionalidade apresenta um potencial heurístico que tem sido cada vez mais debatido como uma forma de necessária resistência também metodológica, opositiva - e criativa - aos cânones interpretativos ainda baseados em uma visão de humanidade advinda, quase que exclusivamente, do norte global e reproduzindo modelos de opressão que reverberam em práticas e atividades que movimentam o conhecimento, a cultura e a sociedade (AKOTIRENE, 2019, p.40).

É preciso frisar que a discussão e o recurso à interseccionalidade aqui comunga da crítica no sentido de que não se pode propor hierarquias de opressão e nem mesmo subsumir lutas e reivindicações justificadamente colocadas pelo pensamento decolonial, 


\section{REVISTA PAUTA GERAL \\ ESTUDOS EM JORNALISMO \\ 10.5212/RevistaPautaGeral.v.7.15837}

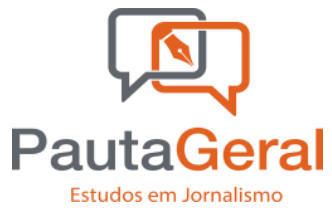

mas procurar dar centralidade aos modos que repercutem e/ou reproduzem opressões contra grupos e contingentes populacionais historicamente marginalizados, a fim de desconstruí-los.

Recomenda-se, pela interseccionalidade, a articulação das clivagens identitárias, repetidas vezes reposicionadas pelos negros, mulheres, deficientes, entre outros grupos considerados minoritários, para finalmente defender a identidade política contra a matriz de opressão colonialista, que sobrevive graças às engrenagens de um racismo cisheteropatriarcal capitalista (AKOTIRENE, 2019, p. 45).

Portanto, a partir desta matriz teórica trazida pelo pensamento decolonial, uma observação das práticas mediáticas, do campo jornalístico, e das imagens fotojornalísticas, em particular, não pode prescindir de um olhar crítico acerca dos atravessamentos destes marcadores, onde os acontecimentos e sujeitos aos quais se reportam, cotidianamente, permaneçam isentos de uma discussão aprofundada sobre seu posicionamento neste contexto, pois mesmo quando em tom de denúncia, são, muitas vezes, submetidos aos quadros visuais e informativos pré-fixados por critérios limitadores, tais como noticiabilidade, agendamento ou protocolos de cobertura, já que são constituintes e constituidores de uma prática jornalística, e comunicacional, linear (LEAL; ANTUNES, 2019). Trata-se do desafio de debater em que medida as imagens, no âmbito jornalístico, tem alcançado os sujeitos que retratam, ou ainda, se somos nós, espectadores moralmente enquadrados, que atribuímos a estas imagens jornalísticas o empenho de realidade esperado. Espera-se que exerçam uma função emancipadora ou prescritiva, afinal?

Há várias dificuldades para que o "aparecimento" de sujeitos vulneráveis nas imagens não seja reduzido à desumanização, mas permita entrever seres dotados de dignidade, de humanidade e de agência. Enquadramentos vitimizantes impedem que os sujeitos consigam libertar sua capacidade de aparecer na cena pública, reforçando o regime representativo das imagens (RANCIĖRE, 2010, 2012). "Aparecer", como mencionamos, não é só adquirir visibilidade, mas envolve alterar o modo como sujeitos são percebidos e reconhecidos diante dos outros, o que demanda um deslocamento do olhar, uma outra forma de imaginar as relações com a alteridade e de considerar as formas de vida daqueles que se apresentam diante de nós (MARQUES; BIONDI, 2019).

Sob esse aspecto, a imagem funciona como operação sensível que expressa uma batalha constante entre regimes figurativos e representativos de visibilidade, que 


\section{REVISTA PAUTA GERAL \\ ESTUDOS EM JORNALISMO \\ 10.5212/RevistaPautaGeral.v.7.15837}

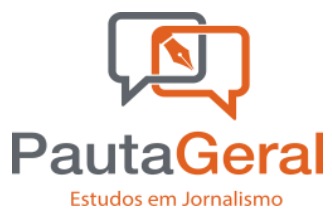

persistem em reduzir a multipliciade de formas de vida, de temporalidades e de modos de expressão que tecem a rede de manutenção cotidiana da vida dos sujeitos. Segundo Rancière (2010), a capacidade de aparecer manifesta-se em uma espécie de perturbação da ordem sensível que pode revelar a fratura causada por representações preconceituosas que aprofundam desigualdades.

Nem sempre as imagens que encontramos promovem uma abertura para que ocorra o deslocamento do olhar do espectador. Contudo, quando algumas delas escapam à rotulação imediata, alterando, na circulação ampliada, sentidos já fixados por valores e quadros de julgamento, há uma ruptura, um intervalo. Esse intervalo requer do espectador uma contemplação mais detida, tornando possível refletir acerca de uma dimensão política das imagens, entendendo a política em um sentido amplo, como os jogos discursivos que influenciam na percepção do que é dado a ver, sentir, ouvir e falar (RANCIÈRE, 2012). Partimos do pressuposto de que imagens destinadas a produzir um certo atestado de realidade, como aquelas feitas sob o regime jornalístico, podem oscilar, em uma tensão dialética, entre uma representação que afirma expectativas e uma ruptura capaz de instaurar uma prática de dissenso fundada em um intervalo, uma fratura que permite outras aberturas de sentido.

Deste modo, o esforço desta discussão passa por observar e analisar os modos através dos quais o jornalismo, enquanto um dos mediadores centrais em nossa sociedade, promove ou referencia lugares e posições aos sujeitos, a partir de suas próprias imagens produzidas, elaboradas e difundidas. Neste intento, tomamos a fotografia vencedora do maior prêmio de fotojornalismo internacional, o World Press Photo, laureada na edição de 2019. Intitulada Crying girl on the border, a foto foi registrada por John Moore, profissional norte-americano, que cobria a chegada de um grupo latino-americano, composto por mulheres e crianças, à fronteira dos EUA com o México, situado em McAllen, Texas, em junho de 2018.

$\mathrm{Na}$ imagem (Figura 1), o flagrante de uma revista a uma mulher abordada por uma/um agente de fiscalização da fronteira. Identificada como mulher apenas pelo reconhecimento da compleição física entrevista no enquadramento dado ao seu corpo, a personagem aparece de perfil apoiando os braços em um automóvel e, enquanto as mãos da/do agente (também não identificada/o para além do uniforme) Ihe fixam a cintura, uma criança, em pé, ao seu lado, é a única a ter parte do rosto revelado e visto em choro. De 


\section{REVISTA PAUTA GERAL}

\section{ESTUDOS EM JORNALISMO}

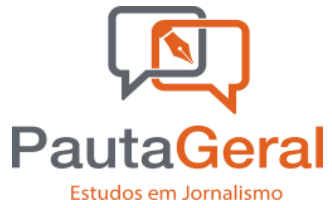

Estudos em Jornalismo

frente para a situação de revista, a criança é a única personagem com uma reação e expressão retratadas na imagem.

Por inferência, atribuímos uma identidade feminina à personagem abordada, por inferência, também atribuímos a condição de maternidade desta mulher. Abordadas, fiscalizadas, mulher e criança são as personagens femininas que, frequentemente, figuram a travessia de grupos latino-americanas que arriscam suas vidas deixando para trás, não raro, histórias de violência, precariedade, insegurança, perseguição, entre outras circunstâncias, em tentativas, em geral, precárias, de entrar nos EUA em busca de melhores condições de vida. Porém, interditadas, tais personagens femininas aparecem tanto no limite da fronteira quanto da imagem em questão. O médio plano, a tomada da distância, a iluminação ambiente entre as sombras projetadas e o veículo, a ênfase no perfil e alinhamento dos corpos no momento flagrante da revista constituem elementos visuais que, em conjunto, tem a finalidade de garantir o caráter ilustrativo da ação corriqueira de abordagem policial a estas pessoas.

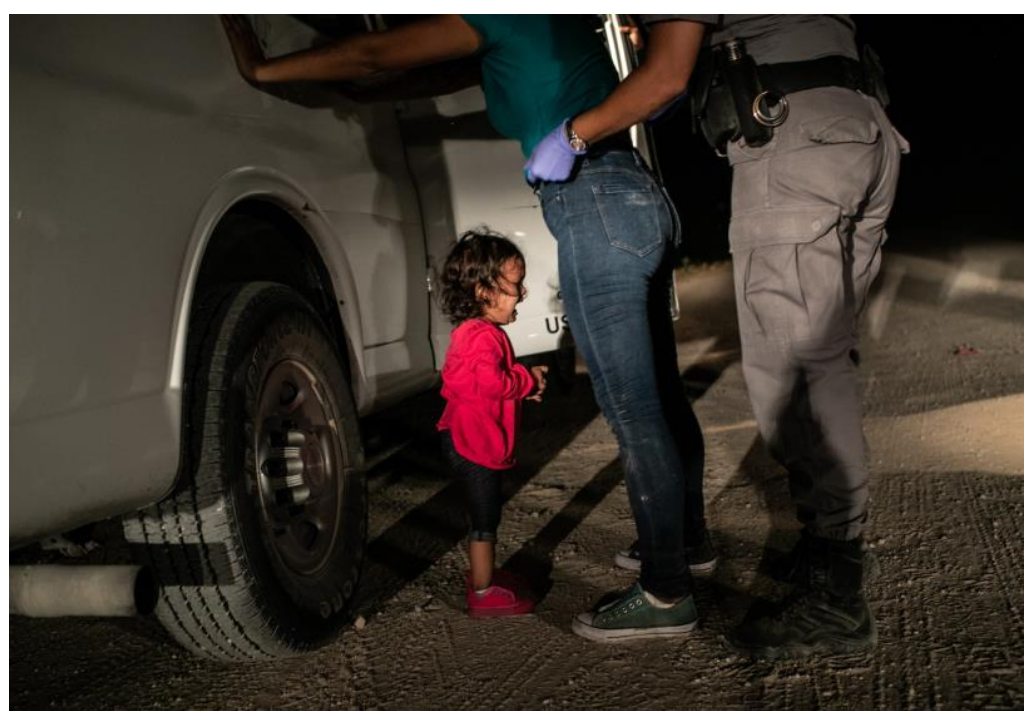

Figura 1: John Moore, 12 junho 2018.

Fonte: Disponível em https://www.worldpressphoto.org/collection/photo/2019/37620/1/John-Moore Acesso em junho 2019.

É importante notar que a mulher, mestiça, terceiro-mundista, latina, carrega a tradição dos rótulos e do interdito. O tema da fotografia, que ilustra as ações de abordagem e captura de mulheres e crianças na divisa estadunidense com o México, tem sido, inclusive, alvo de inúmeras críticas na imprensa mundial, além das declarações e relatórios publicados por diversas instituições de Direitos Humanos, justamente por 
terminar na separação entre mães e suas crianças. Entre outras situações registradas de mulheres grávidas sem atendimento, mães com filhos portadores de síndrome de Down, entre outras deficiências, mulheres e crianças enfrentam, indistintamente, situações de vigilância, detenção, atendimento médico precário ou insuficiente, ofensas pessoais, além de deportações solitárias. Deste modo, diferentes interdições se sobrepõem a estas mulheres, uma vez que, impedidas de entrar no país são quase sempre deportadas desacompanhadas de seus filhos e filhas, que permanecem cativos por semanas ou meses em campos de detenção 4 para imigrantes, muitos deles, sem qualquer documento.

Neste contexto, discutir a colonialidade do gênero, como explica Lugones, possibilita a entender a opressão como uma interação complexa de um sistema, simultaneamente econômico, racializante e engendrado culturalmente. No exemplar aqui discutido, a intrínseca relação entre as políticas racializadas de migração e policiamento não passam despercebidas de outros veículos de comunicação, que a repercutem.

Começo aqui a fornecer uma forma de compreender a opressão de mulheres subalternizadas através de processos combinados de racialização, colonização, exploração capitalista, e heterossexualismo. [...] Chamo a análise da opressão de gênero racializada capitalista de 'colonialidade do gênero'. Chamo a possibilidade de superar a colonialidade do gênero de 'feminismo descolonial' (LUGONES, 2014, p. 941).

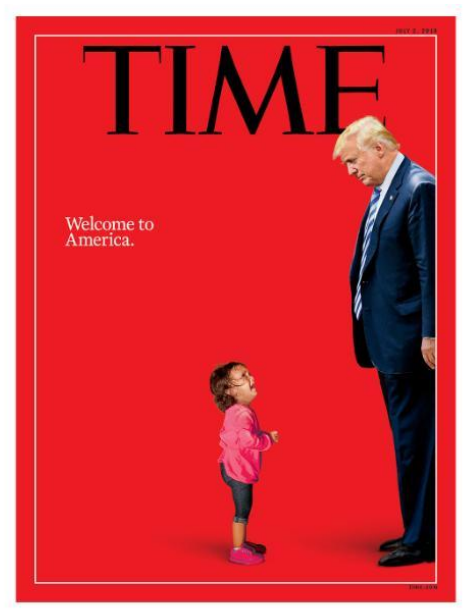

Figura 2: Time. Edição de 02 julho 2018.

Fonte: Disponível em https://www.tellerreport.com/life/--john-moore-wins-world-press-photo-with-the-iconicimage-of-the-honduran-girl-separated-from-her-mother-on-the-us-border-.HJ41h2TYV.html Acesso em junho 2019. 4 Informações disponibilizadas pelo Relatório Mundial 2019, Human Rights Watch.
Disponível em https://www.hrw.org/pt/world-report/2019 Acesso em janeiro 2020. 


\section{REVISTA PAUTA GERAL \\ ESTUDOS EM JORNALISMO

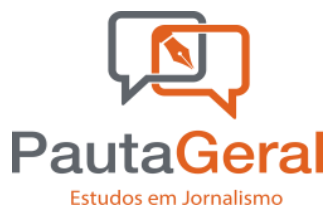

Na edição de 02 de julho de 2018 (Figura 2), a capa da revista Time utiliza da mesma fotografia para compor outra ilustração acerca das interdições na fronteira e mistura o registro fotográfico do flagrante da abordagem policial registrada por Moore com a fotografia de Donald Trump, retirada em outra ocasião.

Os personagens são colocados frente a frente, como em um encontro/confronto de olhares. Suas diferenças de tamanho podem ser compreendidas como a reiteração irônica das diferenças de escalas entre dois povos, dois mundos, duas naturezas, dois tipos de sujeitos. Assimétrica, a distinção marcada e encarnada no olhar, na postura e na desproporção entre Trump e a criança migrante, ilustra o próprio sistema colonial ainda postulado no cruzamento das normatizações opressoras de uma forma de racismo cisheteropatriarcal atribuindo à garota migrante, a figuração das desigualdades estruturantes da posição de gênero, raça, etnia, classe e discriminações.

A revista Time nos propõe, em suma, uma legenda (implícita) que vai explorar ainda mais o sentido destas fraturas promovidas pela dualidade e polarização existente nas figuras do par colonizador/colonizado estabelecidas, na imagem, pela hierarquia entre os sujeitos feita, também, como uma hierarquização de olhares. Daí, não poder escapar a ironia colocada pelo título que "mancheta" a imagem: Welcome to America aparece em um fundo uniforme vermelho que poderia facilmente remeter à histórica, mas sempre atual, violência dos EUA para com os povos latinos, fronteiriços, com todas as implicações problemáticas de assujeitamento que esta relação de poder ainda coloca. "O processo de colonização inventou os/as colonizados/as e investiu em sua plena redução a seres primitivos, menos que humanos, possuídos satanicamente, infantis, agressivamente sexuais, e que precisavam ser transformados" (LUGONES, 2014, p. 941).

$\mathrm{Na}$ imagem, ao se descaracterizar, ao desinvestir as migrantes pela interdição, elas não poderiam estar em nenhuma outra posição senão o lugar do outro, diminuído, assujeitado, infans sem fala. E aqui, é preciso sublinhar que a elaboração da imagem jornalística, embora em viés irônico, acaba mantendo as posições dicotômicas e hierárquicas presentes na relação dual entre as personagens. Ainda não se pode ouvir o choro e nem a voz da hondurenha Sandra Sanchez, nem da criança, Yanela Sanchez. Deste modo, também pela imagem se exerce a colonialidade de gênero dada pela linguagem, pois uma tradução vigora como uma prática colonial quando apaga a possibilidade de resistência a ela oferecendo, em seu lugar, uma legibilidade específica. 
REVISTA PAUTA GERAL

ESTUDOS EM JORNALISMO

10.5212/RevistaPautaGeral.v.7.15837

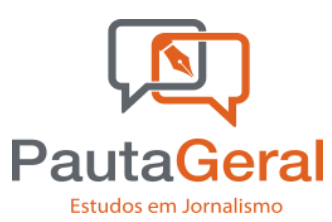

Estudos em Jornalismo

"Assim, ver a colonialidade é revelar a degradação mesma que nos dá duas interpretações da vida e um ser interpretado por elas" (LUGONES, 2014, p.946).

\section{A consideração das formas de vida na figuração das migrantes pela imagem}

Um dos aspectos desfigurantes da identidade dessas duas mulheres migrantes é justamente essa construção colonial que quer acentuar, de um lado, a posição de vítima dos sujeitos retratados e, de outro, o lugar virtuoso ocupado pelo espectador que pode se dizer indignado e compadecido pela situação enquadrada na narrativa jornalística. A imagem em questão tende a reforçar o fato de que quando as fotografias jornalísticas mostram mulheres em situações de sujeição e opressão, parece que elas acionam um enquadramento que predispõe o público a assumir um ponto de vista moral que oscila entre a condenação e a indignação, a sideração e a consideração, num movimento que não contraria o direcionamento dos espectadores a um lugar de avaliadores virtuosos diante da precariedade e vulnerabilidade daqueles que são mostrados como "incapazes" de sobreviver e de agir. Como afirma a pesquisadora Tania Perlini (2012), essas imagens não têm uma função crítica, dificilmente interrogam o espectador acerca das razões da subalternização e da sujeição do corpo feminino, mas fornece instrumentos morais específicos para a configuração de um posicionamento "confortável" aos espectadores.

Desprovidos de nome e de história, as duas figuras femininas (assim como o agente oficial de imposição da lei e da força) aparecem diante de nós através da mediação de uma imagem que não oferece oportunidade de dúvida ou contemplação, uma vez que juízos condenatórios ou de revolta são acionados de modo instantâneo. Desta forma, há pouca abertura, nessa imagem, para uma "indecidibilidade moral", ou seja, para uma avaliação moral equívoca, não resolvida, que interpela à reflexão crítica e coloca em dúvida parâmetros e pressupostos que delineiam uma legibilidade e inteligibilidade ao mundo.

Uma imagem que mobiliza a indecisão e questiona o lugar de "júri virtuoso" ocupado pelos receptores não aceita explicações rápidas e nem adere tão facilmente às avaliações morais dos espectadores (PERLINI, 2012). Ela escapa aos esquematismos, dialoga com outras imagens e descortina algumas das dinâmicas dos dispositivos que as fazem existir. A imagem que aqui analisamos organiza e dispõe causalmente os fatos, em vez de evocar, pelo relato, e pela falha do relato, a captura das complexidades dos modos de vida e das formas de vida de sujeitos migrantes. É uma imagem que explica e julga em 
vez de sugerir e preservar o difícil gesto de apreender, considerar e reconhecer as alteridades. Ela sidera, mais do que considera.

A diferença entre os gestos de siderar e considerar é traçada por Marielle Macé (2018) quando ela identifica que a condição de ser reconhecido está ligada a disposições mais gerais que preparam ou modelam um sujeito para o reconhecimento a partir de sua sideração ou de sua consideração. Essa autora nos chama a atenção para a condenação das vidas que atualmente tentam se manter em meio à condição de precariedade, vulnerabilidade, mas que chegam até nós através de enquadramentos que não nos permitem perceber ou escutar seus gestos, sonhos, tentativas de melhoria e experiências (migrantes, sujeitos empobrecidos, vítimas de grandes catástrofes, vítimas de violência institucional, etc.). Os enquadramentos que regulam a aparição e a apreensão desses modos de vida são geralmente destinados a produzir a sideração, tanto daqueles que olhamos, quanto nossa própria sideração e alheamento:

Siderar, deixar-se siderar é permanecer medusado, petrificado,
enclausurado numa emoção que não é fácil transformar em moção,
aterrado numa hipnose, numa estupefação, num enfeitiçamento em que
se esgota de algum modo a re-erva de partilha, laços, gestos que
poderiam ser alimentados pelo conhecimento que temos dessas
situações, mas que permanece como um sofrimento à distância.[...]
Considerar seria levar em conta os vivos, suas vidas efetivas, uma vez
que é desse modo e não de outro que essas vidas são furtadas ao
presente - levar em conta suas práticas, seus dias, e então
desenclausurar o que a sideração enclausura; não designar e rotular
vítimas, mas descrever tudo o que cada um põe em ação para lidar com
situações de vulnerabilidade. (MACÉ, 2018, p.28)

Considerar é um convite para a contemplação e para a reabertura de uma relação, de uma proximidade, de uma possibilidade de avizinhamento com a alteridade. Seria uma forma de reconhecimento que privilegia a responsabilidade pelo outro, a atenção e o cuidado com sua trajetória e com suas demandas. Uma ética da responsabilidade que desafia os quadros normativos da justiça e do direito no sentido de requerer uma outra forma de avaliarmos uns aos outros, privilegiando o acolhimento e não a condenação sumária de quem se mostra diferente. Seria uma provocação para descolarmos o reconhecimento da compaixão, da tolerância e da caridade, para produzirmos uma forma de justiça na qual não só seja possível nos surpreendermos pelo outro, mas também trabalharmos sobre uma outra possibilidade de sermos quem somos.

É precisamente esse o desafio: "Como experimentar essas vidas como semelhantes e dessemelhantes? Como não singularizá-las ao extremo?" (MACÉ, 2018, 


\section{REVISTA PAUTA GERAL \\ ESTUDOS EM JORNALISMO \\ 10.5212/RevistaPautaGeral.v.7.15837}

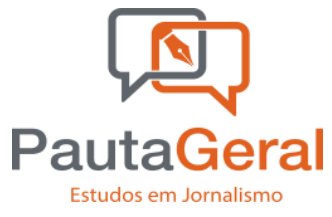

p.31). A consideração implica pensar nos entrelaçamentos entre vida social, identidades, vulnerabilidades, justiça, hospitalidade e condições de existência nas quais imigrantes, refugiados e refugiadas, elaboram constantemente em suas narrativas e buscam, com elas, insistir e resistir a partir da migração e das várias desterritorializações e reterritorializações que ela exige.

Argumentamos que o processo de consideração envolve duas dimensões interligadas: a problematização de enquadramentos que ainda seguem uma lógica colonial de opressão e controle, e a proposição de outras possibilidades de registro narrativo e visual das formas de vida precárias. De um lado, temos o fotojornalismo feito pela grande mídia que nos revela como os significados dominantes numa dada sociedade sufocam e tornam invisíveis as perspectivas particulares de um grupo específico. Não obstante, as fotografias também oferecem traços para pensarmos acerca de como uma forma de vida liminar encontra alternativas de habitar o mundo, de torná-lo habitável e de circular, de modo camuflado, entre os discursos legitimados e legitimantes.

Quando Judith Butler $(2004,2018)$ nos apresenta o conceito de vida precária, ela destaca que os sujeitos e grupos estão diferentemente expostos à injúria, à agressão, à rejeição e à morte. Além disso, ela argumenta que a vulnerabilidade não é só uma condição ontológica, mas um estado contingente que pode ser modificado, alterando o estatuto de um sujeito ou grupo se considerarmos que os vínculos e condições (materiais, simbólicas, humanas) que nos permitem de viver podem ser acionados de modo a compor arranjos que promovam alternativas e potenciais possibilidades de ruptura. Vulnerabilidades não são essenciais, imutáveis, mas são situadas e resultam de uma complexa rede de múltiplas relações. A vulnerabilidade, assim compreendida, nos revela uma maneira relacional de existir que nos desafia a contemplar o outro, a desacelerarmos nossas expectativas de apreensão e categorização rápida e superficial. Compreendê-lo, portanto, requer tempo, requer abrir espaço à aproximação da alteridade, do inquietante outro que se manifesta diante de nós como rosto, como voz que nos interpela eticamente, rompendo todo e qualquer enquadramento explicativo.

Para Butler (2015, p.22), "não há vida e morte sem relação com um determinado enquadramento. Ambas nos são apresentadas dentro de molduras específicas que não apenas estruturam a maneira pela qual passamos a conhecê-las e a identificá-las, mas constituem condições que lhes conferem suporte e legitimidade". Não se trata apenas de uma operação de seleção e saliência de informações: trata-se de uma poderosa operação 
de julgamento e reconhecimento de sujeitos e grupos e das condições sociais e institucionais que permitem a permanência e espraiamento de códigos específicos de valorização e desvalorização desigual das vidas.

Segundo Butler (2015, p.14), as convenções e as normas gerais que agem nos dispositivos de enquadre moldam, por exemplo, um ser humano em um sujeito reconhecível por meio da apreensão, isto é, uma forma de conhecimento associada ao sentir e ao perceber, muitas vezes sem utilizar conceitos (julga-se e condena-se antes de conhecer). O problema, de acordo com Butler (2015, p.20) é tornar evidente como essas normas operam para produzir legibilidades e inteligibilidades através de narrativas capazes de tornar certos sujeitos pessoas reconhecíveis e tornar outros decididamente mais difíceis de reconhecer ${ }^{5}$.

Contra um enquadramento desfigurante presente muitas vezes nos enquadramentos da grande mídia, pelo fotojornalismo, por exemplo, Didier Fassin (2015), assim como Butler, propõe repensarmos as vulnerabilidades como provedoras de uma outra sintaxe ética, como uma ética da responsabilidade que não tem como objetivo condenar os sujeitos a estados crônicos de dificuldades, mas de construir relatos provendo novas ferramentas, habilidades, quadros morais e linguagens alternativas para definir injustiças e politizar injúrias.

Macé (2018) se preocupa, ao refletir sobre a condição de sujeitos migrantes, com o modo através do qual as imagens e relatos auxiliam ou coíbem as possibilidades de consideração das formas que vida que ali oscilam entre representação e figuração, ou seja, entre a adequação a papéis sociais impostos e a afirmação persistente de um "como"; de astúcias que não têm relação com a auto reprodução cega e funcional de normas, mas sim com a maneira possível de habitar o mundo, contra a intolerável aceitação e normalização da desigualdade das vidas. Ela argumenta que a experiência de migrantes, as perdas, rupturas e lutos por vivenciados tem a capacidade de nos revelar a brutalidade dos poderes assimétricos, mas também instauram a possibilidade de:

5 Por meio dos enquadramentos e enredos narrativos, a mídia cria um padrão estético e comportamental a ser adotado pela sociedade como parâmetro de julgamento moral. Esse modelo abrange, majoritariamente, pessoas brancas, com visuais e conflitos incomuns a negros. Assim, eles são forçados a adaptar-se para se encaixar em um padrão, que naturalmente não os contempla, e a omitir os seus próprios conflitos, pois não estão em pauta, e, consequentemente, não merecem espaço para discussão. Portanto existe o preconceito que eles sofrem, por serem estrangeiros, por não falarem o português, por serem pobres e principalmente, por serem negros. 


\section{REVISTA PAUTA GERAL}

\section{ESTUDOS EM JORNALISMO}

10.5212/RevistaPautaGeral.v.7.15837

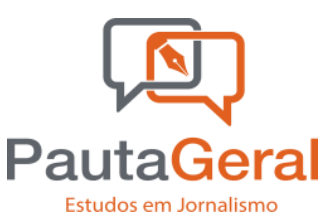

Estudos em Jornalismo

[...] pensarmos nos limiares multiplicados, nos espaços inabitáveis e contudo habitados, nos migrantes que apreendemos por suas penas e perdas, que percebemos apenas como espectros, no impossível lado a lado, na memória fraquejante, com o sentimento de sideração que nasce disso tudo e a violência que essa sideração autoriza cotidianamente. É importante falarmos das vidas que se mantêm, que tentam se manter ou têm que se manter em pleno acampamento; de migrantes que não apreenderíamos apenas por sua invisibilidade e por sua distância em relação à maior parte de nossas vidas; mas a quem nos reportaríamos também por seus gestos, seus sonhos, suas tentativas e sua experiência. Poderíamos falar então do movimento de consideração, de observação, de atenção, delicadeza, cuidado, estima, reabertura de uma relação, de uma proximidade, de uma possibilidade (MACÉ, 2018, p.27-28).

Imagens fotográficas que permitem a consideração sobre o outro são também aquelas que oferecem condições à figuração, ou seja, que "faz falar duas vezes o rosto dos anônimos": por um lado, "como testemunhas mudas de uma condição inscrita diretamente em seus traços, suas roupas, seus modos de vida"; e, por outro, "como detentores de um segredo que nunca iremos saber, um segredo roubado pela imagem mesma que nos traz esses rostos" (RANCIĖRE, 2012, p. 23-24). Dito de outro modo, enquanto a representação tende a imobilizar e fixar sujeitos em categorias que os definem e os submetem; a figuração revela o quão difícil (e mesmo impossível) é reter os sujeitos e a complexidade de suas experiências e modos de vida em uma imagem. Na figuração, o sujeito tem que escapar à nossa tentativa incessante de tudo categorizar, avaliar, julgar e submeter ao já familiar: ele deve permanecer estranho, não familiar e, por isso mesmo, inquietante.

Uma imagem não se resume a uma escolha dicotômica entre a sideração e a consideração, assim como ela não abrange só representação ou só figuração. Nos interessa justamente mostrar quando e como passagens entre essas dimensões podem acontecer e que forma assumem na materialidade da imagem, em sua relação com a implicação ou o convite ao olhar do receptor.

\section{À guisa de conclusão: por um olhar decolonial no fotojornalismo}

No caso da imagem aqui analisada, as dimensões interseccionais que atravessam a criação de um enunciado específico permite pensar em como os corpos, rostos, paisagens e objetos podem ser lidos e estudados a partir de um ponto de vista comunicacional, político, estético e ético. Para a produção de um olhar decolonial são necessários lampejos e curto-circuitos que interrompem a linearidade de uma possível 


\section{REVISTA PAUTA GERAL}

\section{ESTUDOS EM JORNALISMO}

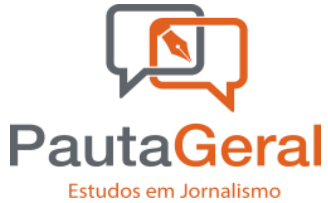

Estudos em Jornalismo

história daqueles e daquelas que sobrevivem/sobreviveram às vulnerabilidades associadas à migração forçada e despertam, no espectador, novos modos de percepção da imagem, do corpo e do espaço da cena. O que está em jogo aqui não é uma revelação do mundo habitado por esses sujeitos migrantes, mas a possibilidade de olhar a história de novo, de desprogramar o olhar, de trazer posicionamentos variados e considerar seus efeitos no presente (POIVERT, 2010).

Assim, acreditamos ser central mostrar como as imagens, dialeticamente, tornam sensíveis - acessíveis, legíveis e dignas de consideração - a vida e a sobrevivência dos sujeitos em situação de vulnerabilidade, ao mesmo tempo em que elas declaram a impotência dos sujeitos oprimidos em situações que os expõem à violência, ao silenciamento e, justamente por isso, demandam outras formas de acolhimento, consideração e hospitalidade.

Em relação com a capa da revista Time, e a diversidade de contextos nos quais a fotografia (assim como as icônicas imagens do menino sírio Aylan Kurdi ou da menina vietnamita Kim Puc) compareceu produzida e elaborada para distintas finalidades artística, publicitária, jornalística -, podemos afirmar que a imagem analisada é um entre vários elementos textuais em uma rede ou diagrama em que se dispõem e se articulam diferentes enunciados, atores, forças e fluxos em circulação. A reflexão trazida à luz do pensamento decolonial oferece, portanto, uma possibilidade de repensar os modelos sistematizados e normativos que mantém a invisibilidade destes sujeitos.

No campo jornalístico, a produção de figuras e representações ilustrativas, sem densidade, que nutrem ainda os distintos contextos de circulação social, reitera posições e consensos estigmatizantes, tanto quanto propõem modos normalizados e hierarquizados de olhar. E é justamente como parte de um complexo diagrama que resulta de processos de midiatização e de circulação que a figuração pode conectar formas de vida na imagem e para além dela: a biopotência minoritária pode agir sobre a biopolítica do controle, ao revelar como as vulnerabilidades situadas e desafiadas podem desenhar formas de vida para mulheres migrantes que não são facilmente classificáveis, pois são excessivas; existem entre identidades, sobrevivem e escapam à tentativa de serem capturadas. É nos gestos não capturáveis, ambíguos e que geram indecidibilidade nas formas hegemônicas de produção de legibilidades dos corpos e das vidas que pode atuar a biopotência. 
Na fotografia, note-se, o corpo da mulher aparece sem uma cabeça, sem sua face, sem qualquer traço de sua singularidade. No entanto, sua filha assume a vocalização do rosto, do apelo ético e biopotente de suas existências que atua na definição do que é uma vida humana e do que conta como vida sem subestimar as potencialidades, táticas, realizações, imaginários e solidariedades que thes permitem escapar dos constrangimentos que pesam sobre elas. Essas mulheres migrantes são sobreviventes e buscam criar uma forma de vida que lhes garante um rosto a ser contemplado num jogo de enunciação e de invenção de uma cena dissensual que tematiza os danos causados pela persistente colonialidade de gênero.

\section{Referências}

AKOTIRENE, Carla. O que é interseccionalidade. São Paulo: Sueli Carneiro - Pólen, 2019.

ANZALDÚA, Glória. "La conciencia de la mestiza: rumo a uma nova consciência". Estudos Feministas, Florianópolis, v.13, n.3, p.704-719, 2005.

BUTLER, Judith. Quadros de guerra: quando a vida é passível de luto? Rio de Janeiro: Civilização Brasileira, 2015.

BUTLER, Judith. Precarious Life. London: Verso, 2004.

BUTLER, Judith. Corpos em Aliança. Rio de Janeiro: Civilização Brasileira, 2018.

CALLEGARO, Adriana; LAGO, María Cristina. La crónica latinoamericana: cruce entre literatura, periodismo y análisis social. Quórum Académico, vol. 9, núm. 2, juliodiciembre, p. 246-262, 2012.

CARON, Carole. Humaniser le regard. Du photojournalisme humanitaire à l'usage humanitaire de la photographie. Commposite, Paris, v.1, p.1-19, 2007.

CASTRO-GÓMEZ, Santiago; GROSFOGUEL, Ramón (orgs.). El giro decolonial: reflexiones para una diversidad epistémica más allá del capitalismo global. Bogotá: Siglo del Hombre Editores; Universidad Central, Instituto de Estudios Sociales Contemporáneos y Pontifi cia Universidad Javeriana, Instituto Pensar, 2007.

CRUZ, Guilherme Silva da. Narrativas do poder: o jornalismo narrativo como outra ferramenta de representação da política e do poder na América Latina. Anais Eletrônicos do Congresso Epistemologias do Sul, Foz do Iguaçu, v. 1, n. 1, p. 103-108, abr., 2017.

Jornalismo narrativo: uma reflexão sobre representações políticas e simbólicas da América Latina. Chasqui. Revista Latinoamericana de Comunicación, n.141, abril-julio, p. 349-364, 2019. 
FASSIN, Didier. At the heart of the State: the moral world of institutions. London: Pluto Press, 2015.

FERRARESE, Estelle.; LAUGIER, Sarah. Formes de vie. Paris: CNRS Éditions, 2018.

LEAL, Bruno; ANTUNES, Elton. Desafios metodológicos à pesquisa sobre gênero e comunicação: reflexões a partir de narrativas de um problema cotidiano. Compós, Porto Alegre, 2019.

Disponível em http://compos.org.br/anais texto por gt.php?idEncontro=Mig. Acesso em junho 2019.

LEAL, Bruno. Do corpo como texto: na mídia, na rua. Revista Fronteiras, Porto Alegre, v. 8, p.144-151, 2006.

LOPES, Maria Immacolata Vassalo de. A teoria barberiana da comunicação. Revista Galáxia, vol. 12, n. 1, p. 39-63, 2018.

LUGONES, Maria. Rumo a um feminismo descolonial. Estudos Feministas, Florianópolis, v.22, n.3, p.935-952, 2014.

MACÉ, Marielle. Siderar, considerar: migrantes, formas de vida. Rio de Janeiro: Bazar do Tempo, 2018.

MARQUES, A. C. S.; BIONDI, A. G. . O doméstico tem um gênero: figurações de mulheres empobrecidas no discurso visual do fotojornalismo. Revista Latinoamericana de Ciencias de la Comunicación, v. 16, p. 86-99, 2019.

MARQUES, A. C. S.; BIONDI, A. G. . Vulnerabilidades no enquadramento biopolítico de mulheres empobrecidas em fotografias jornalísticas sobre o Programa Bolsa-Família. In: AGUIAR, Leonel; SILVA, Marcos Paulo da; MARTINEZ, Monica; (orgs.). (Org.). Desigualdades, relações de gênero e estudos de jornalismo. 1ed.São Paulo: Life Editora, 2018, v. 1, p. 225-244.

MARQUES, A. C. S.; BIONDI, Angie. (In)visibilidade de mulheres sem rosto: ética e política em imagens fotográficas de Teresa Margolles. Comunicação e Sociedade, v. 32, p. 269-286, 2017.

MARTINO, Luís Mauro; MARQUES, Ângela Salgueiro. Fotografias do limiar: dicotomias, fabulações e temporalidades intervalares em imagens de famílias empobrecidas durante a Depressão norte-americana dos anos 1930. Revista Ínterin, vol. 25, n. 2, p. 83-110, 2020.

MBEMBE, Achille. Necropolítica. Biopoder, soberania, estado de exceção, política da morte. São Paulo: N-1 Edições, 2018.

MIGNOLO, Walter. Desobediência epistêmica: a opção descolonial e o significado de identidade em política. Cadernos de Letras da UFF. Dossiê Literatura, língua e identidade, n.34, p.287-324, 2008.

1 (1), pp. 12-32, 2017.

Desafios Decoloniais Hoje. Epistemologias do Sul. Foz do Iguaçu/PR, 
PERLINI, T. Le pacte moral comme condition d'existence du photojournalisme humanitaire. In: Imaginaires du présent: Photographie, politique et poétique de l'actualité. Cahier ReMix [online], Montreal, $\mathrm{n}^{\circ}$ 1, mai, 2012. Disponível em http://oic.uqam.ca/fr/remix/le-pacte-moral-comme-condition-dexistence-duphotojournalisme-humanitaire Acesso em janeiro 2019.

PERSICHETTI, Simonetta. A encruzilhada do fotojornalismo. Revista Discursos Fotográficos. Londrina, vol. 2, n.2, p. 179-190, 2006.

POIVERT, Michel. Destin de l'image performée. In: La photographie contemporaine. Paris: Flammarion, p. 209-235, 2010.

RANCIÈRE, Jacques. O espectador emancipado. São Paulo: Martins Fontes, 2010. O destino das imagens. Rio de Janeiro: Contraponto, 2012.

ROSA, Ana Paula. Circulação: das múltiplas perspectivas de valor à valorização do visível. Texto apresentado no VI Colóquio Semiótica das Mídias, CISECO. Japaratinga: Alagoas, p.1-17, 2017.

URANGA, Washington. Desarollo, ciudadanía, democracia: aportes desde la comunicacíon. "Integración comercial o diálogo cultural ante el desafío de la sociedad de la información". Texto apresentado no III Congreso Panamericano de Comunicación. Buenos $\quad$ Aires, $2005 . \quad$ Disponível em http://www.washingtonuranga.com.ar/index.php?option=com content\&view=article\&id=25: propios-10\&catid=8:textos-propios\&ltemid=107 Acesso em março 2020.

Recebido: 06 junho/2020

Aprovado: 30 julho/2020 